Fourth International Conference on Sustainable Construction Materials and Technologies http://www.claisse.info/Proceedings.htm

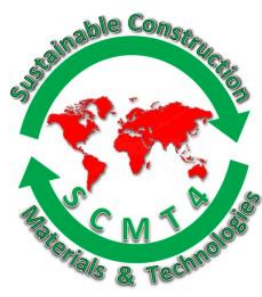

SCMT4

Las Vegas, USA, August 7-11, 2016

\title{
Stress Generation in Mass Concrete Blocks with Fly Ash and Silica Fume - An Experimental and Numerical Study
}

\author{
H. A. Khalifah ${ }^{1 \mathrm{a}}$, M. K. Rahman ${ }^{1 \mathrm{~b}}$, Zakariya Al-Helal ${ }^{1 \mathrm{c}}$, and Sami Al-Ghamdi ${ }^{1 \mathrm{~d}}$ \\ ${ }^{1}$ Consulting Services Department, Saudi Aramco, Dhahran, Saudi Arabia; Research Institute, King Fahd \\ University of Petroleum\& Minerals Dhahran, Saudi Arabia. ${ }^{1 a}$ Email: <hasan.khalifa@aramco.com>, \\ ${ }^{1 b}$ Email :<mkrahman@kfupm.edu.sa>, ${ }^{1 c}$ Email: <zakariya.alhelal@aramco.com>, \\ ${ }^{1 d}$ Email: <sami.ghamdi.9@aramco.com>.
}

\begin{abstract}
A new Economic city project is being built by Saudi Aramco in Jizan, off the coast of Red Sea in Saudi Arabia. It includes a refinery, a sea port and associated infrastructures. The wharves at the sea port is constructed using a large number of massive concrete blocks, $11 \mathrm{~m}$ to $13.7 \mathrm{~m}$ long, $\quad 1.9 \mathrm{~m}$ high and $2 \mathrm{~m}$ in width. Due to heat of hydration of the cement, temperatures in excess of $70{ }^{\circ} \mathrm{C}$ at the core of the block could result in delayed ettringite formation (DEF), and excessive temperature differential between the core and the surface would result in cracking at the surface. Both phenomena would seriously compromise the durability of the blocks in marine environment. To ensure long-term durability and control temperature rise and differentials, the concrete blocks for the wharves were constructed using concrete mix in which $25 \%$ of Portland cement was replaced with Class F fly ash. For achieving strength and durability, additional $7.5 \%$ of cement was replaced with silica fume. This paper presents the field, experimental and numerical investigation conducted for a typical mass concrete blocks used in the wharves. Evolution of temperature at the core and the surface of these blocks, compressive and tensile strength of the concrete mix were measured. The heat of hydration for the concrete mix was determined in laboratory using semi-adiabatic calorimeter. Nonlinear finite element analyses were carried out to investigate the effect of heat of hydration and environmental loading stress generation and crack development in the blocks.
\end{abstract}

\section{INTRODUCTION}

Mass concrete construction often constitutes a challenge and requires significant efforts to control temperature rise due to the heat of hydration of the cementitious materials. Excessive temperature increase leads to thermal gradient between the core of mass concrete and its surface and may cause cracking when the thermal stress in concrete exceeds its tensile strength. Furthermore, a peak temperature in massive concrete elements in excess of $70^{\circ} \mathrm{C}$ may lead to the phenomenon, referred to as a delayed ettringite formation (DEF). Expansive pressures occur in the pores of the concrete during ettringite formation, causing cracking in the hardened concrete. Moreover, a temperature rise above $70^{\circ} \mathrm{C}$ in the fresh concrete mix also causes sulfate to be trapped in hydration products that will be released later, to form ettringite in the meso-pores. The ACI specifications for structural concrete [ACI 301-10] limits the maximum temperature in concrete to $70^{\circ} \mathrm{C}\left(158^{\circ} \mathrm{F}\right)$ to avoid thermal cracking. The ACI committee 207.1 
for mass concrete [ACI 207.1R-05] suggests that a thermal gradient in excess of 22 to $25{ }^{\circ} \mathrm{C}$ may cause cracks in concrete. The temperature generated from the hydration of cement in mass concrete along with low rate of heat dissipation leads to temperature rise in the concrete block. The interior concrete tends to expend, while at a low ambient temperature, the exterior concrete tends to shrink and resist interior concrete to expend, thus causing thermal stress (Figure 1). The high thermal gradient between the center and the surface may cause thermal cracks when the thermal stress in concrete exceeds its tensile strength [Crowley, 2014].

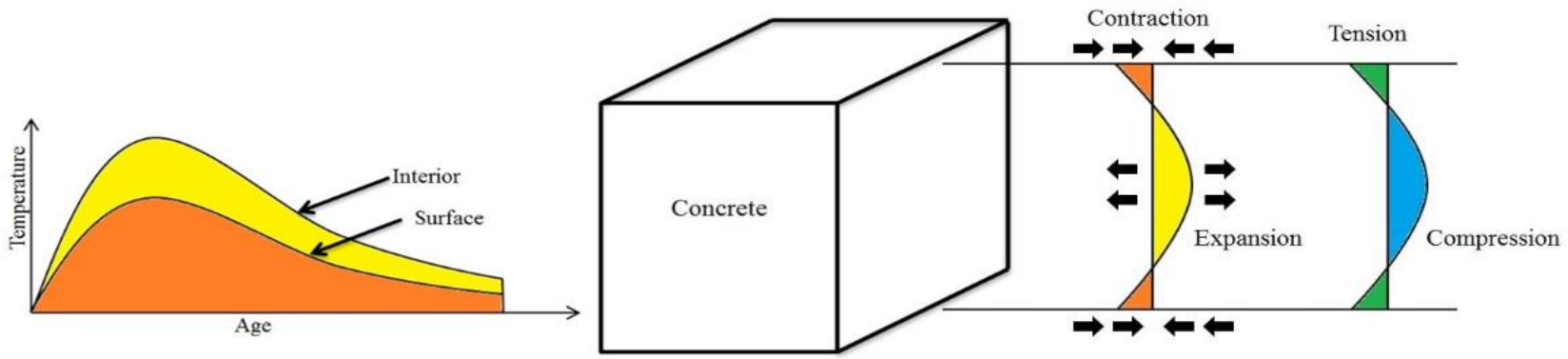

Figure 1. Stress distribution in concrete block due to temperature differential [Crowley, 2014].

Effective measures are required to control the heat generation through various means including, (1) adjustment in the concrete mix through use of supplementary cement material (SCM) that generate less heat, (2) lowering down the fresh mix temperature, (3) using aggregates with low thermal expansion, and (4) through the physical control measure taken after concreting such as cooling pipes and controlled curing water temperature. Excessive differential temperature between the core and the surface of the concrete also needs to be controlled.

Effectiveness of using fly ash as a SCM to reduce heat of hydration has been examined by many researchers. The contribution of fly ash to the overall heat generation is attributed to the Calcium Oxide $(\mathrm{CaO})$ content. Class $\mathrm{F}$ fly ash contains relatively smaller portion of $\mathrm{CaO}$ not exceeding $15 \%$. The heat contribution of Class $\mathrm{C}$ fly ash with $24.3 \% \mathrm{CaO}$ is about $437 \mathrm{~J} / \mathrm{g}$, while for Class $\mathrm{F}$ fly ash with $10.8 \%$ $\mathrm{CaO}$ it is in the range of $194 \mathrm{~J} / \mathrm{g}$ (Schindler and Folliard, 2005). Kim [2010] in his analysis of fly ash effect on heat generation in dam construction shows that $40 \%$ fly ash replacement for Type I cement shows a similar heat generation and compressive strength at 28 days with that of Type IV cement.

The heat of hydration generated in any proposed concrete design mix can be measured by tests in the laboratory to verify its suitability for use in mass concrete application. It can be measured by adiabatic, semi-adiabatic, or isothermal calorimeters [Gerstig and Wisdom, 2010; Gruyaert et al., 2010; RILEM TCE1, 1997]. For major projects, it is also essential to measure the actual temperature rise in a mock-up concrete box. Finite element simulation of the temperature rise in the mass concrete element provides an important insight into the expected temperature rise in mass concrete element and the associated stresses. Modeling and simulating the temperature distribution in mass concrete structures have been proposed by many researchers [Rahman et al., 2013; Kim, 2010]. Also, many empirical models have been developed to quantify the heat of hydration based on the proportioning of the design mix [Lawrence, 1995; Kim 2010].

A new economic city project is being built by Saudi Aramco in Jizan area that includes a refinery, a seaport and associated infrastructure. The wharves of the seaport are being constructed using massive reinforced and unreinforced concrete blocks (Figure 2). In order to control the heat of hydration in these massive blocks and to ensure long-term durability in marine environment, supplementary cement 
materials including fly ash and silica fume were used in these blocks. This paper presents the results of the field monitoring of temperature in a typical mass concrete block and laboratory tests for measuring the evolution of heat of hydration, compressive and tensile strength of the concrete mix with $25 \%$ fly ash used in the blocks. Nonlinear finite element method is used to simulate the temperature rise in concrete due to heat of hydration and to predict the thermal stresses and evaluate the effectiveness of using SCM to control it. The temperature distribution calculated by flow analysis was used as the thermal load for the subsequent structural analysis using MIDAS/Civil finite element software [MIDAS, 2013]. Finite element simulation is carried out for concrete blocks with OPC mix and concrete mix with fly ash and silica fume used in the project.
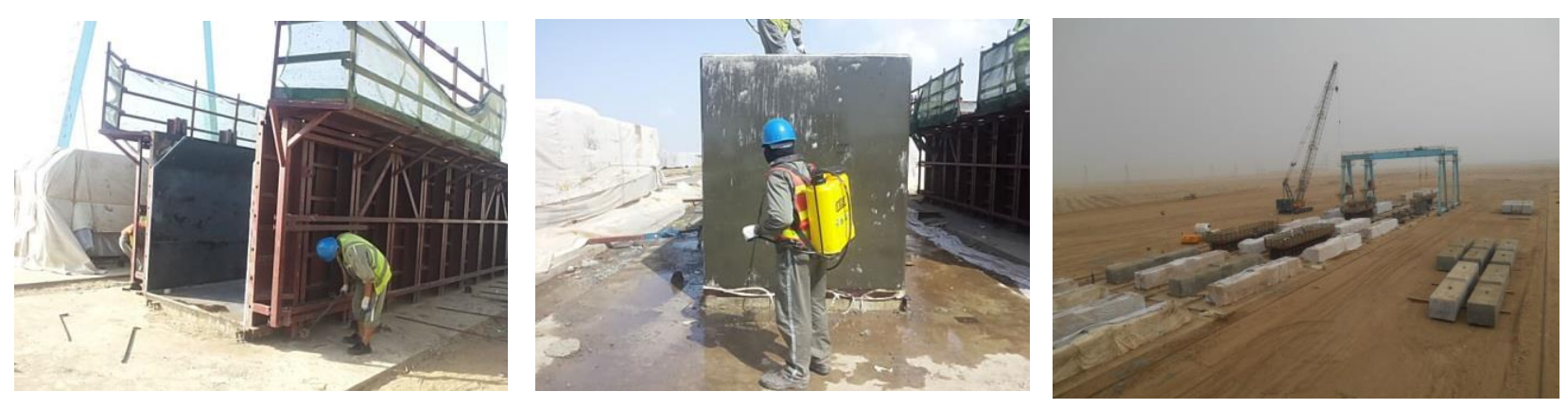

Figure 2. Mass Concrete Blocks for the Wharves at Jizan Seaport

\section{FIELD MONITORING AND LABORATORY INVESTIGATIONS}

Field Monitoring of Temperature Evolution in Blocks. A large number of unreinforced and reinforced mass concrete blocks are being used for the construction of wharves at the seaport. These blocks varying from $11 \mathrm{~m}$ to $13.7 \mathrm{~m}$ in length are $1.9 \mathrm{~m}$ high and $2 \mathrm{~m}$ in wide. The blocks are cast on hardened concrete slab with steel formwork on sides. In order to limit the heat of hydration, a concrete mix in which ordinary Portland cement is replaced with $25 \%$ fly ash and $7.5 \%$ silica fume, with a target compressive strength with $50 \mathrm{MPa}$, was specified for the blocks. The concrete mix used in the concrete blocks investigated contains $334\left(\mathrm{~kg} / \mathrm{m}^{3}\right)$ cement of Type I, $124\left(\mathrm{~kg} / \mathrm{m}^{3}\right)$ fly ash, $37\left(\mathrm{~kg} / \mathrm{m}^{3}\right)$ silica fume with a water/binder ratio of 0.26 . Two types of admixtures Conplast SP500 $\left(6.5 \mathrm{~kg} / \mathrm{m}^{3}\right)$ and Conplast CN $(8$ $\mathrm{kg} / \mathrm{m}^{3}$ ) provided by FOSROC was used in the concrete mix. The coarse aggregate content in the concrete mix was $1380 \mathrm{~kg} / \mathrm{m}^{3}$ and the fine aggregate content was $450 \mathrm{~kg} / \mathrm{m}^{3}$.

The temperature rise due to the heat of hydration in a typical mass concrete blocks, was monitored in the field. Three thermocouples were installed in the blocks at various depths. The thermocouples were installed and embedded in the concrete at the core of the concrete block, near the surface and intermediate point in between as shown in Figure 3. The temperature readings were recorded every hour from the time of starting of concreting for a period of three days. The ambient temperature was also recorded for the same period.

Laboratory Investigations on the Concrete Mix. The laboratory investigations conducted on the concrete mix used in the blocks involved measurement of the heat of hydration using the semi-adiabatic calorimeter. The evolution of compressive and tensile strength at 1, 3, 7,14 and 28 days were measured as per ASTM C39 and ASTM C496 standards respectively. Chloride permeability was also measured at an age of 7 and 28 days using rapid chloride permeability testing (RCPT test) according to ASTM 1202 and the water permeability was measured using $150 \mathrm{~mm}$ concrete cubes as per German Standard DIN 1048 at an age of 28 days. 


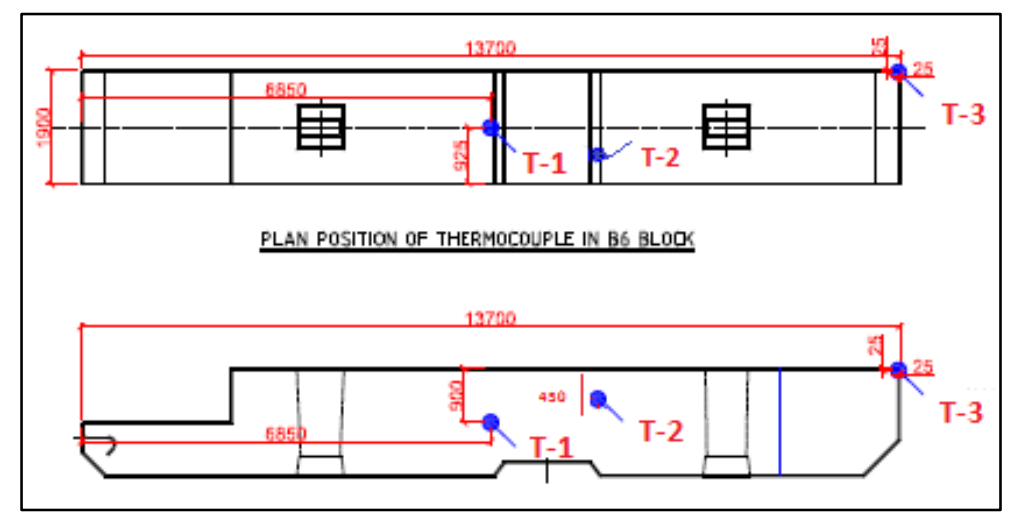

Figure 3. Schematic View of the Thermocouples Installed in the Concrete Blocks.

Heat of Hydration of the Concrete Mix. The heat of hydration of the concrete mix with fly ash and silica fume used in the concrete blocks was measured using iQdrum semi-adiabatic calorimeter. Standard $150 \times 300 \mathrm{~mm}$ concrete specimen was placed inside the iQdrum immediately after mixing the concrete. The calorimeter gives the evolution of the temperature in the concrete sample and thus the heat energy accumulated in the concrete due to the heat of hydration. The heat loss from iQdrum is also measured and the temperature is corrected to account for the heat loss. The test in iQdrum was carried out for duration of 7 days. The adiabatic temperature rise versus time for the concrete mix used in the blocks is shown in Figure 4.

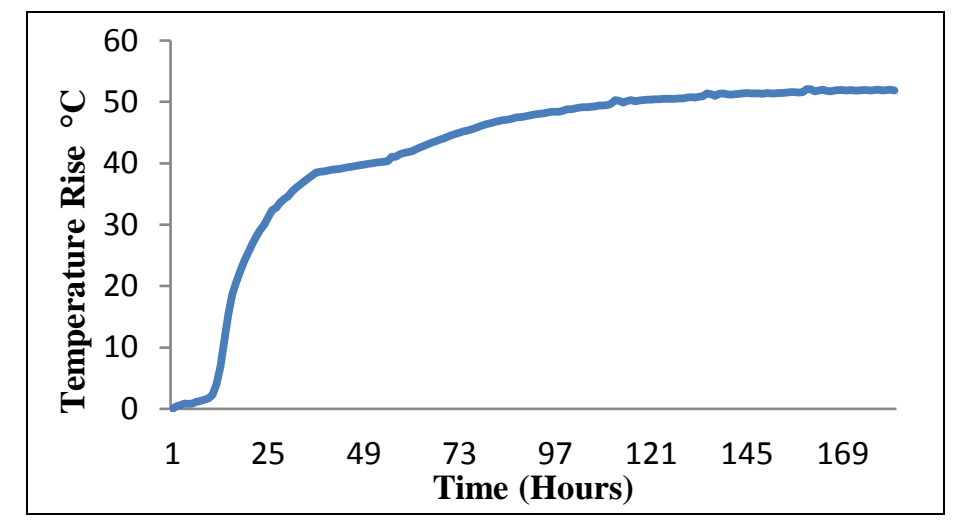

Figure 4. Adiabatic Temperature Rise $\left({ }^{\circ} \mathrm{C}\right)$.

Mechanical Properties of Concrete. Compressive strength tests were conducted on $75 \mathrm{~mm}$ x $150 \mathrm{~mm}$ cylinders for 1, 3, 7, 14 and 28 days as per ASTM C39. The split tensile strength at ages of 1, 3, 7, 14, 28 days were measured as per ASTM C496 on $75 \mathrm{~mm}$ x $150 \mathrm{~mm}$ concrete cylinders. Table 1 shows the results of compressive and tensile strength tests. The specified compressive strength of $50 \mathrm{MPa}$ was achieved at an age of 7 days. The tensile strength at an age of 1 day is $2.5 \mathrm{MPa}$. Since the cracking at early ages due to heat of hydration occurs within 48 hours, early age tensile strength it is critical for crack control in mass concrete. Chloride permeability and water permeability of the fly ash concrete mix are shown in Table 1. The RCPT result shows that an age of 7 days the chloride permeability was "High", whereas after 28 days the chloride permeability reduces significantly and is classified as "Low". Therefore, it is not suitable to expose the concrete blocks to the seawater at an early age. The depth of water penetration at 28 days is $3.5 \mathrm{~mm}$, which is very low. Both results met the standard requirement for high durability of concrete exposed to harsh environment. 
Table 1. Compressive and Tensile Strength Tests

\begin{tabular}{|l|c|c|c|c|c|}
\hline \multicolumn{1}{|c|}{ Properties } & \multicolumn{5}{|c|}{ Age of Concrete (Days) } \\
\hline & 1 & 3 & 7 & 14 & 28 \\
\hline Compressive Strength (MPa) & 31.1 & 48.5 & 52.1 & 63.6 & 70.2 \\
\hline Tensile Strength ( MPa) & 2.5 & 3.2 & 4.8 & 5.1 & 5.3 \\
\hline
\end{tabular}

Table 2. Chloride and Water Permeability Tests

\begin{tabular}{|l|c|c|}
\hline \multicolumn{1}{|c|}{ Concrete Age } & 7 days & 28 days \\
\hline RCPT (ASTM 1202) Total charge passed 6h (Coulombs) & 4934 & 1862 \\
\hline DIN 1048 depth of water penetration (mm) & - & 3.5 \\
\hline
\end{tabular}

\section{FINITE ELEMENT MODELING OF THE BLOCKS}

Nonlinear finite element modeling was carried out to simulate the early age thermal behavior of the mass concrete blocks using commercial software MIDAS/Civil. First a thermal analysis was performed to determine the temperature distribution throughout the concrete block followed by stress analysis to investigate the evolution of stresses. Also, the thermal field in the blocks obtained using semi adiabatic calorimeter results in finite element simulation is compared with the field data to verify its applicability as a predictive model for mass concrete elements. A concrete block having dimensions $2 \mathrm{~m}$ (width) x $13.7 \mathrm{~m}$ (length) x $1.9 \mathrm{~m}$ (depth) used in the construction of wharves was simulated in MIDAS. One quarter of the block was modeled making use of two axes of symmetry. The boundary conditions in the finite element model includes hardened concrete slab contact for the bottom surface, formwork on all sides, and contact with air on the top. The dissipation of heat at the boundaries is principally due to convection. Convecting boundaries are applied to the sides and the top surfaces. Convection depends on types and setting period of the formwork, curing methods, and wind speed. The overall effect of convection is described by Newton's law of cooling as following:

$\mathrm{q}=\mathrm{h} \cdot \mathrm{A} \cdot(\mathrm{Ts}-\mathrm{Ta})$

Where,

q: heat flow $(\mathrm{kcal} / \mathrm{h}), \mathrm{h}:$ convection heat transfer coefficient $\left(\mathrm{kcal} / \mathrm{m}^{2} \cdot \mathrm{h} \cdot{ }^{\circ} \mathrm{C}\right), \mathrm{A}:$ area $\left(\mathrm{m}^{2}\right), \mathrm{Ts}$ : surface temperature $\left({ }^{\circ} \mathrm{C}\right)$, Ta : air temperature $\left({ }^{\circ} \mathrm{C}\right)$

The input parameters for the thermal analysis includes; convection coefficients, ambient temperature, lift placement thickness, internal heat generation rate of concrete, material properties, and thermal boundary conditions. The evolution of compressive and tensile strength and shrinkage of the concrete was also input. Table 3 shows typical values of the input parameters used in finite element simulation. Appropriate values of some parameters were taken from literature. Finite element simulation of the blocks was carried out first for concrete mix using ordinary Portland cement concrete mix. The heat generation and cracking in the blocks were investigated. This was followed by finite element simulation of concrete mix with $25 \%$ fly ash and $7.5 \%$ silica fume actually used in the blocks. 
Table 3. Input parameters for the thermal analysis model

\begin{tabular}{|l|l|l|}
\hline \multicolumn{1}{|c|}{ Parameter } & \multicolumn{1}{c|}{ Unit } & \multicolumn{1}{c|}{ Value } \\
\hline Conductivity & $\mathrm{Kcal} / \mathrm{m} \cdot \mathrm{h} / \mathrm{C}$ & 2.3 \\
\hline Specific Heat & $\mathrm{Kcal} / \mathrm{kg} / \mathrm{C}$ & 0.29 \\
\hline Density & $\mathrm{Kg} / \mathrm{m}^{3}$ & 2400 \\
\hline Placement Temperature & $\mathrm{C}$ & 28 \\
\hline Convection & $\mathrm{Kcal} / \mathrm{m}^{2} \cdot \mathrm{h} \cdot \mathrm{C}$ & 12 \\
\hline Analysis Time & $\mathrm{Hr}$ & 170 \\
\hline Thermal expansion & $/{ }^{\circ} \mathrm{C}$ & $1 \times 10^{-6}$ \\
\hline Poisson Ratio & & 0.18 \\
\hline
\end{tabular}

\section{FE SIMULATION OF THE CONCRETE BLOCK WITH OPC CONCRETE}

Finite element analysis was carried out for the concrete blocks with ordinary Portland cement concrete. The heat generation was simulated utilizing the built-in heat source function in MIDAS. The evolution of temperature and the variation of stresses across the depth in the block were obtained. Figure 5 shows the temperature field in the block at various times after casting. The evolution of temperature over time for points at the surface, center and intermediate location in the block is shown in Figure 6. In OPC concrete mix, the maximum temperature in the core is about $83^{\circ} \mathrm{C}$ and the temperature gradient between the surface and the core of the block is about $40{ }^{\circ} \mathrm{C}$. Both values significantly exceed the limits to prevent DEF and surface cracking. The stresses developed in the block at various times are shown in Figure 7. It can be seen that the tensile stresses at the surface exceeds allowable tensile strength in the period between 25 to 80 hours. This would result in cracking in the concrete block.

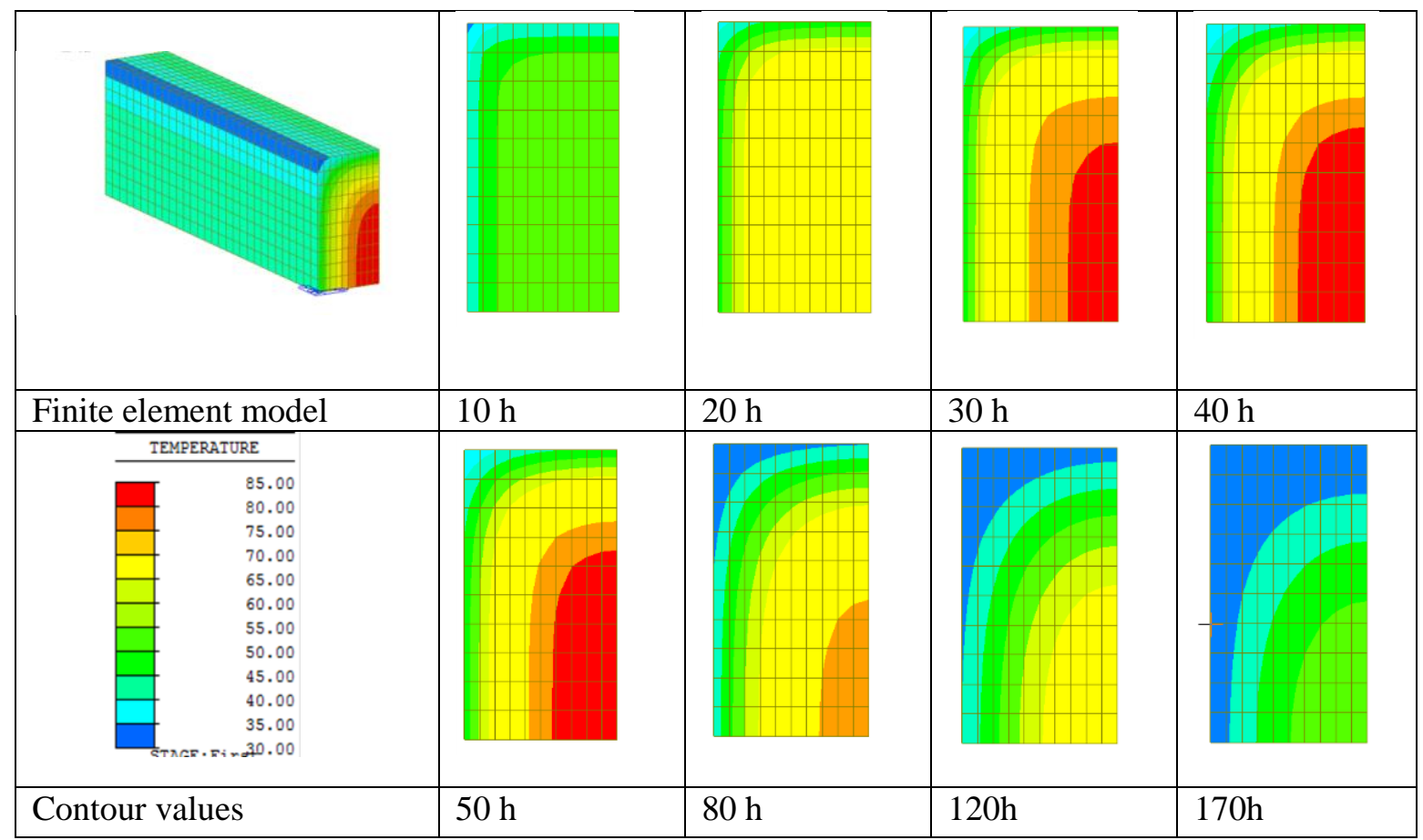

Figure 5. Temperature Contours across the Depth of the Block with OPC Mix. 


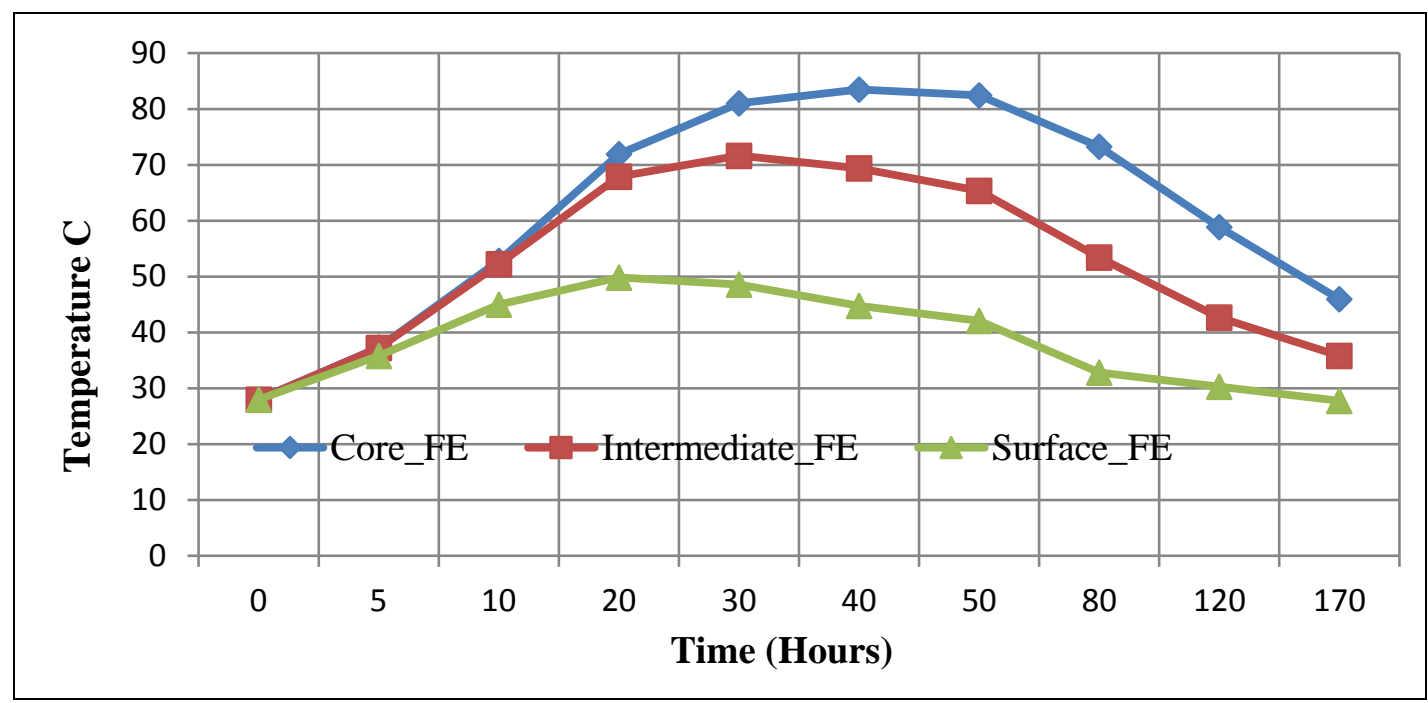

Figure 6. FE Temperature Profiles at Various Locations for the OPC Mix.

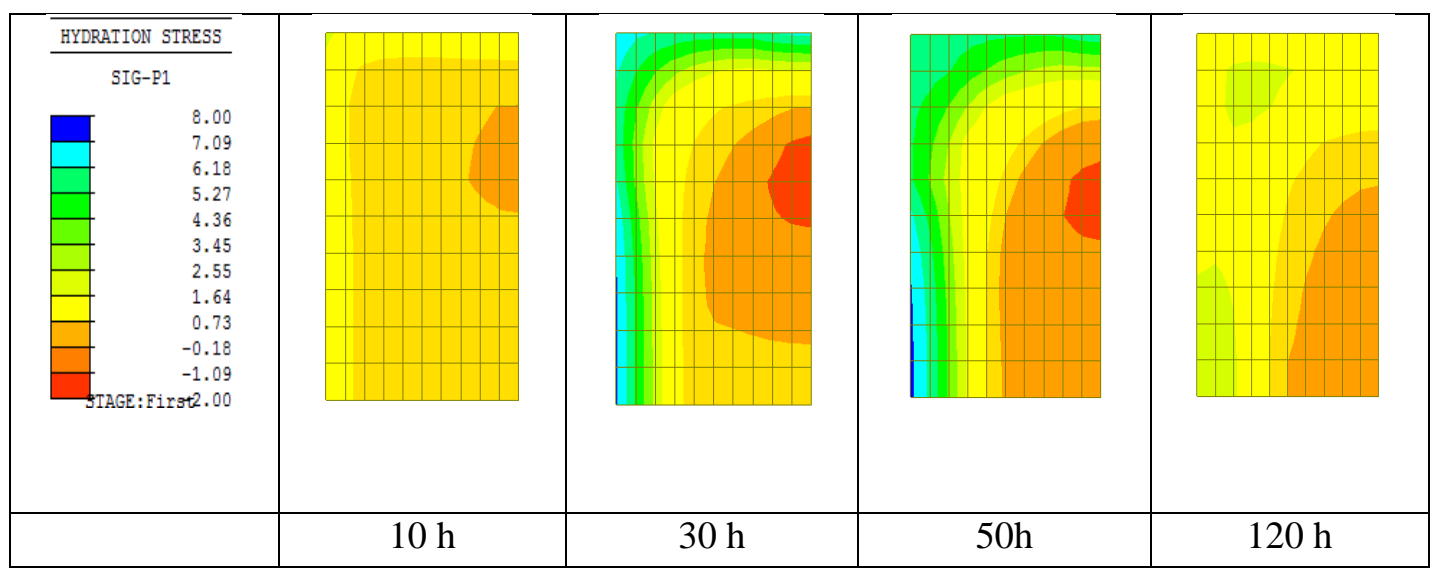

Figure 7. Stress Contours across the Depth of the Block for OPC Mix.

\section{RESULTS OF FIELD MONITORING AND FE SIMULATION OF FLY ASH CONCRETE}

The temperature evolution in the concrete blocks was monitored at 3 locations in all concrete blocks. The peak temperature recorded in the concrete blocks was $64^{\circ} \mathrm{C}$ at the core of the block. The recorded peak temperature was less than $70^{\circ} \mathrm{C}$. The temperature differential between the center of block and its surface was observed to be about $14^{\circ} \mathrm{C}$ and meets project specifications and the ACI standard limits. No cracking was observed in the mass concrete blocks in the field.

The temperature distribution in the concrete block was computed using heat of hydration analysis in MIDAS followed by static analysis for the stresses in the concrete. The results of temperature measured by thermocouples in field and the results obtained from finite element simulation are shown in Figure 8 at locations shown in Figure 3. It can be seen from this figure that the finite element simulation captures the temperature evolution in the concrete block with a good accuracy. The temperature contours across the 
depth of the block at different ages are shown in Figure 9. The finite element simulation shows that the tensile stresses are within allowable limits at the surface of the block as indicated in Figures 10 and 11. The temperature at the core and temperature differential of the fly ash concrete are significantly lower than the OPC concrete mix. The addition of silica fume resulted in higher early age tensile strength in concrete, which precluded the development of cracks on the surface.



Figure 8. Field and FE Temperature Profiles at Various Locations in the Block.

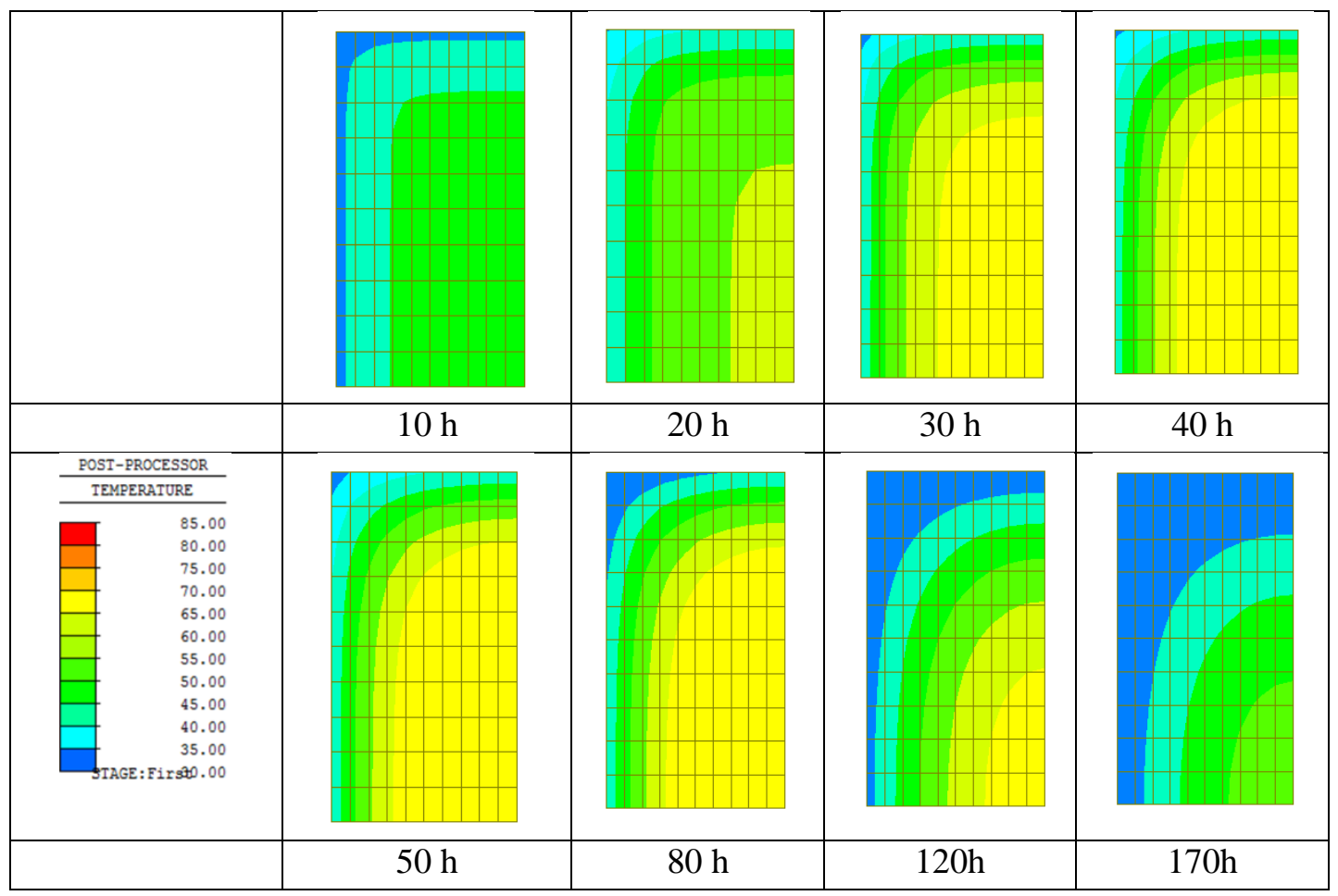

Figure 9. Temperature Contours across the Depth of the Block with Fly Ash Mix. 


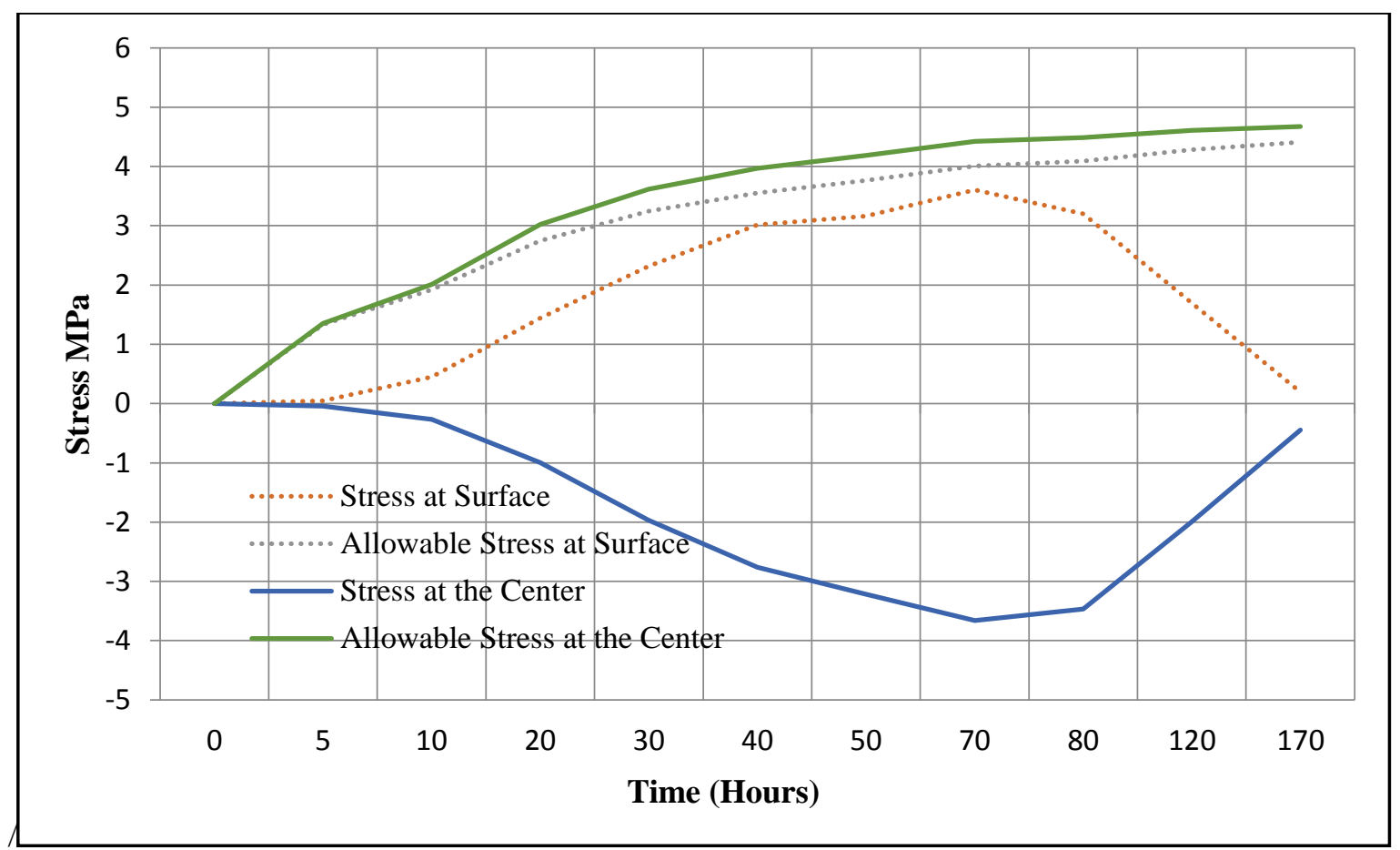

Figure 10. Allowable and Actual Tensile Stresses in the Block with Fly Ash Mix.



Figure 11. Stress Contours across the Depth of the Block with Fly Ash Mix,

\section{CONCLUSION}

Field measurement of temperature was carried out for a mass concrete blocks with dimensions of $13.7 \mathrm{~m} \times 1.9 \mathrm{~m} \times 2 \mathrm{~m}$. The finite element simulation of the heat of hydration and stresses developed in the concrete blocks was carried using laboratory data obtained from semi-adiabatic calorimeter and built in functions within the commercial software Midas Civil. The simulation captures reasonably well the evolution of temperature at various locations in the concrete block when compared with the results of field monitoring. The analysis revealed that the maximum temperature in the concrete block as well as the maximum differential temperature will not exceed industry recommended limits for the mix including OPC $25 \%$ fly ash and $7.5 \%$ silica fume used in the blocks. Moreover, the static analyses indicated that the tensile stresses will be within allowable limits. 


\section{ACKNOWLEDGEMENTS}

The support provided by Consulting Services Department, Saudi Aramco, Research Institute at King Fahd University of Petroleum and Minerals at Dhahran, Saudi Arabia and Saudi Ready-mix are gratefully acknowledged.

\section{REFERENCES}

ACI Committee 207. (2005). "Mass Concrete (207.1R-05)." American Concrete Institute, Farmington Hills, MI, 21 Pages.

ACI Committee 301. (2010). "Specifications for Structural Concrete (ACI 301-10)." American Concrete Institute, Farmington Hills, MI, 77 Pages.

ASTM C 39. "Standard Test Method for Compressive Strength of Cylindrical Concrete Specimens." ASTM International, West Conshohocken, PA, 7 Pages.

ASTM C1202."'Standard Test Method for Electrical Indication of Concrete's Ability to Resist Chloride Ion Penetration." ASTM International, West Conshohocken, PA, 7 Pages.

ASTM C496/C496M. "Standard Test Method for Splitting Tensile Strength of Cylindrical Concrete Specimens.” ASTM International, West Conshohocken, PA, 5 Pages.

Collepardi, M. (2003). "A State-of-the-art Review on Delayed Ettringite Attack on Concrete." Cement and Concrete Composites, 25(4-5), 401-407.

Crowley, A. M. (2014). "Preliminary Research on Development of Surface Resistivity as a Function of Heat Evolution." ACI Fall Convention, 2014.

DIN 1048-5. (1991). "Testing Concrete; Testing of Hardened Concrete (Specimens Prepared In Mould), German Institute For Standardization.

Fu, Y. (1996). "Delayed ettringite formation in Portland cement products." PhD thesis, CNRC, Ottawa, Canada.

Gajda, J., Weber, M., and Diaz-Loya, I. (2014). “A Low Temperature Rise Mixture for Mass Concrete, Concrete International, August 2014, 36(8), p48.

Gerstig, M. and Wisdom, L. (2010). "A Method Based on Isothermal Calorimetry to Quantify the Influence of Moisture on the Hydration Rate of Young Cement Pastes." Cement and Concrete Research, 40(6), 867-874.

Gruyaert, E., Robeyst, N., and De Belie, N. (2010). "Study of the Hydration of Portland Cement Blended With Blast Furnace Slag by Calorimetry and Thermogravimetry." Journal of Thermal Analysis and Calorimetry, 102 (3) 941-951.

Lawrence, C. D. (1995). "Delayed Ettringite Formation: An Issue? In: J. Skalny, S. Mindess (Eds.), Materials Science of Concrete IV." American Ceramic Society, Westerville, OH, 113- 154.

MIDAS/CIVIL (2013). "MIDASIT-Integrated Solution System for Bridge and Civil Engineering." MIDAS Information Technology Co., Ltd. Korea.

Rahman, M.K., Saeed, M.K., Slayee, K. and Baluch, M.H. (2013). "Field Measurement and F.E Modeling of Temperature and Stress Evolution in a Bridge Pile Cap." Proc. of the Seventh International Conference on Concrete under Severe Conditions (PRO 84). Nanjing, China, 272-282. RILEM Publications S.A.R.L. 
Schindler, A.K and Folliard, K.J. (2005). "Heat of Hydration for Cementitious Materials." ACI Materials Journal, January-February, pp. 24-33.

Soo Geun Kim. (2010). "Effect of Heat Generation from Cement Hydration on Mass Concrete Placement" Graduate Theses and Dissertations, Iowa State University.

RILEM TCE1 (1997). "Adiabatic and Semi-Adiabatic Calorimetry to Determine the Temperature Increase in Concrete Due to Hydration Heat of the Cement." Materials and Structures, 30, Oct 1997, 451-464. 